\title{
Investigation of the Influence of the Number of Repetitions on the Process of Laser Marking of HS6-5-2-5 Steel
}

\author{
Lyubomir Lazov \\ Rezekne Academy of Technology \\ Rezekne, Latvia \\ lyubomir.lazov@rta.lv
}

\author{
Nikolay Angelov \\ Technical University of Gabrovo \\ Gabrovo, Bulgaria \\ angelov_np@abv.bg
}

\author{
Edmunds Teirumnieks \\ Rezekne Academy of Technology, \\ Rezekne, Latvia \\ edmunds.teirumnieks@rta.lv
}

\begin{abstract}
Today, methods for marking parts and components in industrial production are constantly improving, and they must meet several basic criteria for active traceability by consumers. The parameter that is of paramount importance for the quality of the marking is related to the contrast of the marked sign or QR code. To achieve optimal contrast, a number of technological factors and the functional relationships between them must be taken into account.
\end{abstract}

The report examines the role of the number of repetitions on contrast in raster marking of HS6-5-2-5 tool steel products. The dependences of the number of repetitions on the speed and frequency are also taken into account - the main factors in the process of laser ablation. Graphs of the depth of the marking are drawn depending on the number of repetitions and the linear density of the pulses. The experiments were made with a fiber laser. By the performed analyses the working intervals of processing between the studied factors are deduced, allowing to achieve the desired optimal result.

Keywords - laser marking, fiber laser, HS6-5-2-5 steel, number of repetitions, linear density of the pulses, speed, power density, contrast.

\section{INTRODUCTION}

Laser marking of metals and alloys is a technological process that is widely used in production. It is used in mechanical engineering, automotive, aircraft, military industry, electronics, in the production of medical equipment, household goods and more.

The technological process of laser marking has been studied in the work of some authors $[1-8]$ :
The paper [1] presents a study of laser micro processing of metals by using a high repetition rate femtosecond laser. On stainless steel (AISI 304), copper and aluminium the impact of the significant laser processing parameters onto the machining process was investigated, such as laser fluency, repetition rate, lateral pulse distance and polarisation. The machining results were evaluated by the ablation rate, surface roughness, process efficiency, material removal rate and the wall-angle. For complementary discussions the experimental data are compared with results achieved in theoretical analysis. Outgoing from the results appropriate laser processing parameters are derived in order to optimise the machining process.

The basic factors affecting the laser marking of products - volumetric density of the absorbed energy and the number of repetitions, were studied in the publication [2]. Experiments were conducted of marking the samples of stainless steel with fiber laser. The dependence of the contrast of marking from the power density for different number of repetitions, and also the volumetric density of the absorbed energy from speed was obtained and the experimental results analysed.

The report [3] presents the results of the measurements and analysis of the influence of laser process parameters on the color contrasting obtained. In this case, the relevant parameter, the field of high frequencies and low pulse energy were examined. It describes studies a properties of the laser radiation, such as, pulse width, average power, the intensity and beam diameter.

Laser marking tests are carried out on AISI 304 steel, using a Q-switched diode pumped Nd:YAG laser in [4]. 
The aim is to determine the correlation occurring between working parameters (i.e. pulse frequency, beam scanning speed, and current intensity) and resulting mark visibility. The latter is evaluated as the contrast index measured from digital images of the marks. To characterize mark features, its width and roughness are estimated, and analyses employing optical and scanning electron microscopy coupled with energy dispersive X-ray technique were carried out. An empirical model was built, and from it the best processing conditions for optimum mark visibility, taking into account the operating constraints of the laser system used, were drawn.

The paper [6] presents the results of the measurements and analysis of the influence of laser process parameters on the colour obtained. The study was conducted for titanium (Grade 2) using a commercially available industrial pulsed fiber laser. It was determined how a variety of different laser process parameters, such as laser power, the scanning speed of the material, the temperature of the material, the size of the marked area, and the position of the sample, relative to both the focal plane and the centre of the working field of the system, affect the repeatability of the colours created. Additionally, a comparison of the results for titanium with those obtained for stainless steel in a previous study is presented.

The influence of a number of basic quantities on the process of laser marking of metals and alloys as well as their mutual connection during the realization of the process is still not clarified. Also, lasers and laser marking systems are constantly being improved, which undoubtedly expands their application capabilities [9-12].

The aim of the development is to study the influence of the overlap coefficient when marking HS6-5-2-5 tool steel products with a fiber laser for different values of speed and linear density of the pulses.

\section{THEORETICAL ASPECTS}

The laser marking process is influenced by a number of physical quantities such as power density, speed, frequency and duration of pulses, pulse power, pulse energy, linear pulse density, linear energy density, effective energy, overlap coefficient, fill factor, coefficient of reflection, absorption capacity, wavelength of laser radiation, coefficient of thermal conductivity, coefficient of diffusivity, specific heat capacity, etc. In each specific case of marking (depending on the material, laser, marking method) studies must be performed. Numerical and / or real experiments can be performed to determine the optimal parameters of the technological process. The speed and linear density of the pulses are quantities that have a significant impact on the studied process.

Marking speed is one of the most important parameters of the technological process. The time of impact on the sample and the energy that is absorbed in the material in the impact zone depend on it. It is decisive in choosing the method of marking.

The requirements for the speed in the technological process of laser marking are contradictory: on the one hand, the speed must be high in order to reduce the time for performing the operation, and therefore to obtain greater efficiency in the production of the product; on the other hand, it must be relatively small in order to be able to absorb the required amount of energy under the influence in order to reach the required temperature and contrast of the marking. By taking into account the other factors influencing the process, a balance must be found between these contradictory requirements and optimal technological parameters must be obtained to achieve laser marking with the required contrast.

Linear density of the pulses is a physical quantity equal in number to the number of pulses dropped per unit length

$$
L_{p}=\frac{v}{v}
$$

where $v$ is the frequency, $v$ - the marking speed.

It is a quantity of complex character. It is determined both by a quantity related to the laser source (marking speed) and by a quantity related to the technological process (marking speed). Linear density of the pulses affects the contrast and homogeneity of the resulting marking.

For each drawn square, the contrast was determined by measuring the Grey colour saturation of the resulting marking $J_{x}$ and the background of the sample $J_{f}$. The contrast of the marking was determined by the formula.

$$
k^{*}=\frac{J_{x}-J_{f}}{J_{b}-J_{f}} \times 100 \%
$$

where $J_{b}$ is the saturation of the black colour

\section{MATERIAL AND LASER SYSTEM}

The experiments were performed with samples of HS65-2-5 rapid tool steel. It is widely used in industry. Steel HS6-5-2-5 is used for making cutters, turning knives, cutting strips for wood and steel, for roughing and semifinishing tools when machining advanced alloy and stainless steels in conditions of increased heating of the cutting edge. It is high carbon steel and has a high content of chromium, molybdenum, tungsten, vanadium and cobalt. Some physical characteristics of the steel are given in Table 1.

TABLE 1. BASIC PHYSICAL CHARACTERISTICS OF THE HS6-5-2-5 RAPID TOOL STEEL

\begin{tabular}{|l|l|}
\hline Characteristic & Value \\
\hline Coefficient of thermal conductivity $k, \mathrm{~W} /(\mathrm{m} . \mathrm{K})$ & 27 \\
\hline Specific heat capacity $c, \mathrm{~J} /(\mathrm{kg} . \mathrm{K})$ & 460 \\
\hline Density $\rho, \mathrm{kg} / \mathrm{m}^{3}$ & 8200 \\
\hline Coefficient of diffusivity $a, \mathrm{~m}^{2} / \mathrm{s}$ & $7.16 \times 10^{-6}$ \\
\hline
\end{tabular}

The experiments were performed with a laser technological system with a fiber laser. Some of its basic parameters are presented in table. 2. The fiber laser is an innovative laser operating in pulsed mode. The wavelength of its radiation is in the near infrared region. It has 
extremely high beam quality and high efficiency. The laser system has high positioning accuracy.

TABLE 2. BASIC PARAMETERS OF A LASER TECHNOLOGICAL SYSTEM WITH A FIBER LASER

\begin{tabular}{|l|l|}
\hline Parameter & Value \\
\hline Wavelength $\lambda, \mathrm{nm}$ & 1064 \\
\hline Power $P, \mathrm{~W}$ & 20 \\
\hline Diameter of working spot $d, \mu \mathrm{m}$ & 35 \\
\hline Frequency $v, \mathrm{kHz}$ & 80 \\
\hline Pulses duration $\tau, \mathrm{ns}$ & 100 \\
\hline Pulse energy $E_{p}, \mathrm{~mJ}$ & 0.25 \\
\hline Pulse power $\mathrm{P}_{\mathrm{p}}, \mathrm{kW}$ & 2.50 \\
\hline Beam quality $\mathrm{M}^{2}$ & $<1.1$ \\
\hline Positioning accuracy, $\mu \mathrm{m}$ & 2.5 \\
\hline Efficiency, $\%$ & 40 \\
\hline
\end{tabular}

\section{EXPERIMENTS}

The study of the influence of the number of repetitions on the process of laser marking of samples of alloy tool steel HS6-5-2-5 was performed in two directions:

1. Investigation of the dependence of the contrast of the marking on the speed

Samples of the study steel were prepared. A raster method of marking was applied. Squares with a side of 5 $\mathrm{mm}$ were marked once, twice, three times and five times. The marking speed varied in the interval $v \in[40,220]$ $\mathrm{mm} / \mathrm{s}$ throug $20 \mathrm{~mm} / \mathrm{s}$. The parameters that are kept constant are presented in Table 3. The marked sample from HS6-5-2-5 steel is given in Fig. 1. The contrast for each mark was determined. Five contrast measurements were made at different locations in each square and the mean contrast value was determined.

TABle 3. PARAmeters that DO NOT CHANGE DURING THE EXPERIMENTS.

\begin{tabular}{|l|l|}
\hline Parameter & Value \\
\hline Power density $q_{s}, \mathrm{~W} / \mathrm{m}^{2}$ & $7.66 .10^{9}$ \\
\hline Diameter of work spot $d, \mu \mathrm{m}$ & 35 \\
\hline Frequency $v, \mathrm{kHz}$ & 20 \\
\hline Pulse duration $\tau, \mathrm{ns}$ & 100 \\
\hline Raster step $\Delta x, \mu \mathrm{m}$ & 50 \\
\hline Defocus $\Delta f, \mathrm{~mm}$ & 0 \\
\hline
\end{tabular}

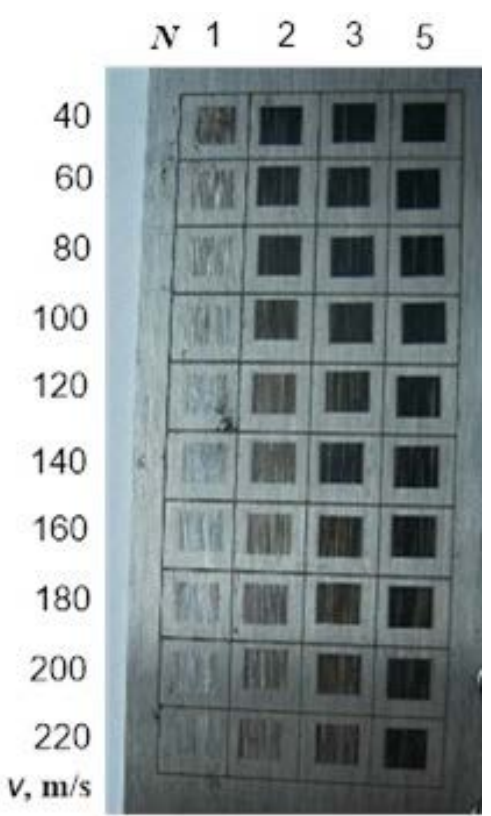

Fig. 1. Sample of tool steel HS6-5-2-5 marked with fiber laser

Results analysis

The graphs of the experimental dependence $k^{*}=k^{*}(v)$ are presented in Fig. 2 for different number of repetitions of the marked squares: $N=1 ; 2 ; 3$ and 5 . The following conclusions can be done from their analysis:

- As the number of repetitions increases, the contrast of the laser marking increases nonlinearly;

- When the speed changes in the interval интервала $v \in[40,100] \mathrm{mm} / \mathrm{s}$ in the double raster marking of the lines the contrast $k^{*}$ increases by about $62 \%$ compared to their single marking (the graphics in orange and red, respectively). When the speed changes in the interval $v \in[100,220] \mathrm{mm} / \mathrm{s}$ this increase is about 2 times. The explanation for this experimental result is that the first treatment increases the absorption capacity in the impact zone. Thus, when re-acting on the treated surface, more energy is absorbed by the incident laser radiation;

- $\quad$ The number of repetitions $N=3$ and $\mathrm{N}=5$ results in a higher contrast $k^{*}$ of the marked area compared to that of $\mathrm{N}=2$, but the increase in contrast is about $25 \%$ and $40 \%$ respectively. These results show that for laser marking of the studied tool steels it is not necessary to do a large number of repetitions (greater than $\mathrm{N}=2$ ). This leads to a loss of time and energy to perform the marking, which increases the production cost of 
the product. In this case, the quality of the marking does not change noticeably;

- Double marking should also be used when the power of the laser source is not sufficient to obtain a quality marking on a single marking. For example, a contrast $k^{*}=37 \%$ is obtained (see Fig. 2) at a speed $v=40 \mathrm{~mm} / \mathrm{s}$ for the used power density and the marking is well perceived when using special readers. A contrast $k^{*}=60 \%$ is obtained (see Fig. 2) for double marking at the same parameters and the marking is well perceived both visually and when using special readers.

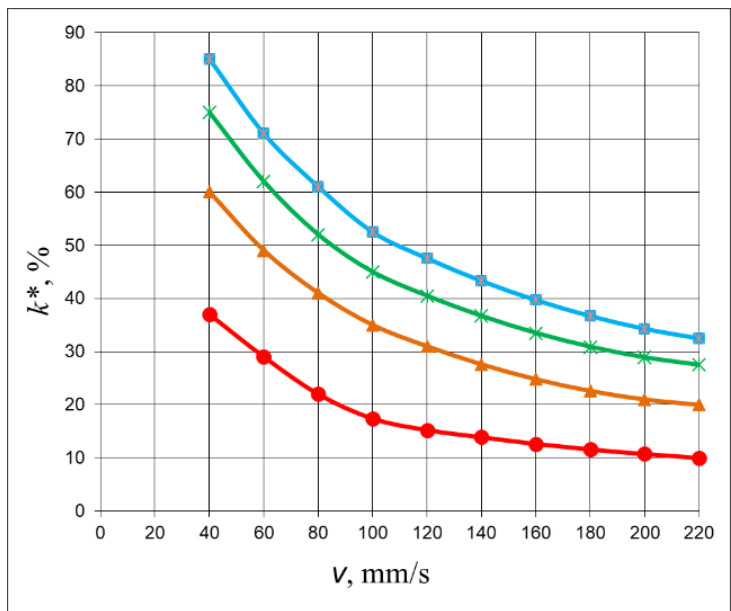

Fig. 2. Graphs of the experimental dependence $k^{*}=k^{*}(v)$ for marking with fiber laser at number of repetitions: red color $-N=1$; orange color - $N=2$; green color $-N=3$; blue color $-N=5$.

2. Investigation of the dependence of the contrast of the marking on the linear density of the pulses

The raster marking method was used again. Squares with a side of $5 \mathrm{~mm}$ were marked once, twice and three times. The linear pulse density varied in the interval $L_{p} \mathrm{C}$ $[125,1000] \mathrm{mm}^{-1}$ throug $125 \mathrm{~mm}^{-1}$. The parameters that are kept constant are presented in Table 4. The contrast was determined for each marked square. Figure 3 shows a sample with a single (top row) and double marking (bottom row) with power density $q_{s}=7.66 .10^{9} \mathrm{~W} / \mathrm{m}^{2}$.

TABLE 4. PARAMETERS THAT DO NOT CHANGE DURING THE EXPERIMENTS.

\begin{tabular}{|l|l|}
\hline Parameter & Value \\
\hline Power density $q_{s}, \mathrm{~W} / \mathrm{m}^{2}$ & $7.66 .10^{9}$ \\
\hline Diameter of work spot $d, \mu \mathrm{m}$ & 35 \\
\hline Speed $v, \mathrm{~mm} / \mathrm{s}$ & 80 \\
\hline Pulse duration $\tau, \mathrm{ns}$ & 100 \\
\hline Raster step $\Delta x, \mu \mathrm{m}$ & 50 \\
\hline Defocus $\Delta f, \mathrm{~mm}$ & 0 \\
\hline
\end{tabular}

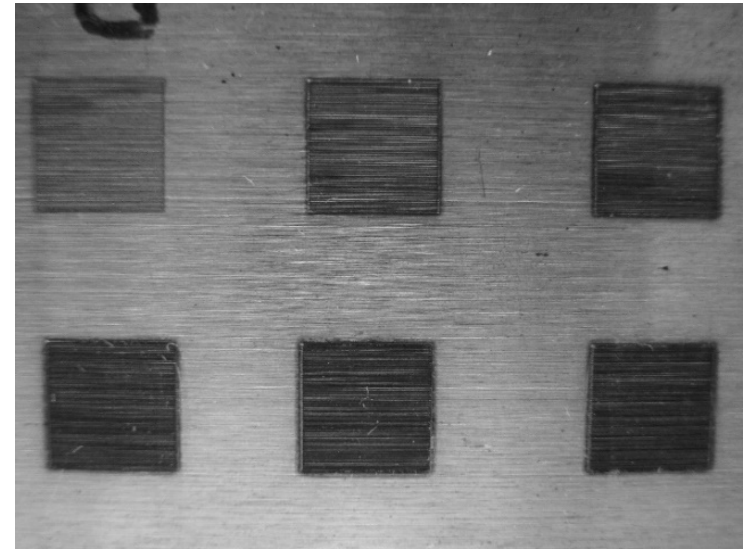

Fug. 3. Single (top row) and double (bottom row) raster marked fields with fiber laser

Results analysis

The graphs of the experimental dependence $k^{*}=k^{*}\left(L_{p}\right)$ are presented in Fig. 4 for different number of repetitions of the marked squares: $N=1 ; 2$ and 3. Several conclusions follow from the analysis of the graphs:

- As the linear density of the pulses increases, the contrast of the marking increases nonlinearly for all three graphs;

- In the interval $L_{p} \in[125,375] \mathrm{mm}^{-1}$ the curves are significantly steeper than in the interval $L_{p} \mathrm{C}$ $[375,1000] \mathrm{mm}^{-1}$;

- At number of repetitions $N=2$ the contrast is from $25 \%$ to $55 \%$ higher than at number of repetitions $N=1$ for the whole studied interval of the linear pulse density;

- At number of repetitions $N=3$ the increase of the contrast is from $40 \%$ to $100 \%$ greater than at number of repetitions $N=1$ for the whole studied interval of the linear density of the pulses;

- Again, it is seen that the required number of repetitions should not be greater than $N=2$.

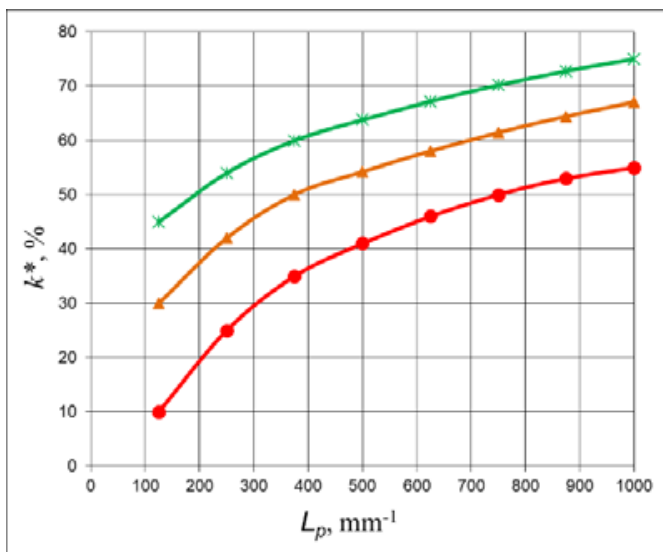

Fig. 4. Graphs of the experimental dependence $k^{*}=k^{*}\left(L_{p}\right)$ for marking with fiber laser at number of repetitions: red color $-N=1$; orange color - $N=2$; green color $-N=3$. 


\section{CONCLUSIONS}

The study we present in this report shows the direct relationship between the contrast in the marking area and the number of repetitions. The relationship between the contrast and the processing speed in the range from 40 $\mathrm{mm} / \mathrm{s}$ to $220 \mathrm{~mm} / \mathrm{s}$ with single and multiple repetitions of the laser impact zone was also analysed.

The influence of the linear energy density (pulse tracking frequency in combination with the processing speed) on the contrast in single and multiple repetitions of the marked area was also analysed.

The correct assessment of the impact of these technological parameters on the contrast of the marking made on samples of HS6-5-2-5 rapid tool steel contributes to the optimization of the production process and increases the wear resistance of the marking and the efficiency of automated QR codes reading to track the quality of the products.

\section{REFERENCES}

[1] Schille, J., et al., Micro processing of metals using a high repetition rate femto second laser: from laser process parameter study to machining examples. in Proc. of 30th Int. Congress on Appl. of Lasers and Electro-Optics (ICALEO 2011), Orlando FL, USA, 2011, DOI: $10.2351 / 1.5062326$

[2] Angelov, N., Investigating the Influence of the Number of Repetitions and Volumetric Energy Density on Laser Marking of Products, Contemporary Materials V-2, Vol. 5 No. 2, 250-253, 2014, DOI: https://doi.org/10.7251/cm.v2i5.1738

[3] Lazov, L., H. Deneva, P. Narica, Factors Influencing the Color Laser Marking, Environment. Technology. Resources, Rezekne, Latvia, Proceedings of the 10th International Scientific and Practical Conference. Volume I, 102-107, 2015, DOI: 10.17770/etr2015vol1.223

[4] Leone, C., S. Genna, G. Caprino, I. De Iorio, AISI304 stainless steel marking by a Q-switched diode pumped Nd:YAG laser",
Journal of Materials Processing Technology 210, 1297-1303, 2010, DOI: https://doi.org/10.1016/j.jmatprotec.2010.03.018

[5] Dolchinkov, N., Practical Research Of Marking And Cutting Of Textiles With Increased Resistance, Using $\mathrm{CO}_{2}$ Laser, Journal of Physics: Conference Series , Volume 1681, 2020012014 IOP Publishing DOI: 10.1088/1742-6596/1681/1/012014

[6] Antonczak, A., B. Stepak, P. aweł E. Koziol, K. Abramski, Krzysztof, The Influence of process parameters on the laser induced coloring of titanium, Applied Physics A 115(3):10031013, 2013, DOI: $10.1007 / \mathrm{s} 00339-013-7932-8$

[7] Wellershoff, S.-S., Untersuchungen zur Energierelaxationsdynamik in Metallen nach Anregung mit ultrakurzen Laserpulsen, in Fach-bereich Physik, Freie Universität Berlin: Berlin, 2000, 159 p., ISBN 3898251322, 9783898251327

[8] Dichev, D., I. Zhelezarov, T. Karadzhov, N. Madzharov and D. Diakov, "Method for measuring motion parameters of moving objects," 12th International Scientific and Practical Conference on Environment, vol. 3, 27-31, 2019, DOI: 10.17770/etr2019vol3.4131

[9] Yasa, E,J.-P. Kruth, Investigation of laser and process parameters for Selective Laser Erosion, Precision Engineering, Volume 34, $\begin{array}{llll}\text { Issue } & 1, & 101-112, & 2010,\end{array}$ https://doi.org/10.1016/j.precisioneng.2009.04.001

[10] Nolte, S., et al. High Repetition Rate Ultrashort Pulse Micromachining with Fiber Lasers. in Fiber Laser Applications: Optical Society of America, 2011, DOI: https://doi.org/10.1364/FILAS.2011.FThC1

[11] Dolchinkov, N., N. Nichev, Structure and Management of the National Automated System for Permanent Control of the Radiation Gamma Background in Bulgaria, Land Forces Academy Review, Vol. XXII, No 2(86), 115-121, 2017, DOI: https://doi.org/10.1515/raft-2017-0016

[12] Pencheva T., D. Pulov, B. Gyoch, M. Nenkov, Design of CCD Optical System for Thermal IR Spectral Region. In pr. 29-th International Spring Seminar fn Electronics Technology, St. Marienthal, Germany, Verlag Dr. Markus A. Detert, 413-418, 2006, ISBN 3-934142-23-0, DOI: 10.1109/ISSE.2006.365380 